\title{
Experimental investigation of CNC machining of elliptical pockets on AISI 304 stainless steel
}

\section{Divyangkumar Dharmendra Patel ${ }^{*}$}

\author{
Mechanical Engineering Department, \\ Sardar Vallabhbhai National Institute of Technology, \\ Surat 395007, India \\ Email: dd.divyang@gmail.com \\ Email: d12me006@med.svnit.ac.in \\ *Corresponding author
}

\section{Hardikkumar Rasiklal Dodiya}

Mechanical Engineering Department,

Sardar Vallabhbhai Patel Institute of Technology,

Vasad 388306, India

Email: er.hardik09@gmail.com

\section{Dr. D.I. Lalwani}

Mechanical Engineering Department,

Sardar Vallabhbhai National Institute of Technology,

Surat 395007, India

Email: dil@med.svnit.ac.in

\begin{abstract}
The shape of a pocket geometry, a tool path strategy and various machining parameters (speed, feed rate, and depth of cut) affect pocket machining process in terms of machining time, surface finish, material removal rate, tool life, etc. Most of the literature related to pocket machining deals with the tool path generation and the effect of various machining parameters. But, the effect of the shape of a pocket geometry and the tool path strategy on the overall performance of pocket machining is scarcely reported. In the present work, an attempt has been made to investigate the effect of aspect ratio (i.e. changing the shape of pocket), feed rate and tool path strategies (zig-zag, spiral and contour parallel) on tool path length, cutting time, percentage utilisation of tool and average surface roughness in machining of elliptical pocket using design of experiments. A novel concept of percentage utilisation of a tool is developed to compare the different tool path strategies and different aspect ratios. The results show that tool path strategy and aspect ratio are significant factors that affect the tool path length and percentage utilisation of tool, whereas aspect ratio, feed rate and tool path strategy are important factors that affect cutting time and surface roughness.
\end{abstract}

Keywords: AISI 304 stainless steel; ANOVA; analysis of variance; CNC; cutting time; DOE; design of experiments; elliptical pockets; feed rate; HSM; high speed machining; surface roughness; tool path. 
Reference to this paper should be made as follows: Patel, D.D., Dodiya, H.R. and Lalwani, D.I. (2016) 'Experimental investigation of CNC machining of elliptical pockets on AISI 304 stainless steel', Int. J Experimental Design and Process Optimisation, Vol. 5, Nos. 1/2, pp.94-116.

Biographical notes: Divyangkumar Dharmendra Patel is a Researcher and Ph.D. student in Mechanical Engineering Department at Sardar Vallabhbhai National Institute of Technology, Surat. He received his M.Tech from the same university. His research activity focuses on the tool path development and optimisation for high speed pocket machining.

Hardikkumar Rasiklal Dodiya is an Assistant Professor in Mechanical Engineering Department at Sardar Vallabhbhai Patel Institute of Technology, Vasad. He received his M.Tech from the Nirma University. He is engaged in teaching and research work in the area of machining, metal forming and optimisation.

Dr D.I. Lalwani is an Associate Professor in Mechanical Engineering Department at Sardar Vallabhbhai National Institute of Technology, Surat. He is engaged in teaching and research work in the area of machining, optimisation and vibration.

This paper is a revised and expanded version of a paper entitled "A spiral toolpath for machining of elliptical pockets using partial differential equation" presented at 4th International Conference on Materials Processing and Characterization, Hyderadabad on 14-15 March 2015 and published in Materials Today: Proceedings 2(2015) 3394-3402. doi: 10.1016/ j.matpr.2015.07.314

\section{Introduction}

Industries all around the world strive continuously for lower cost solutions with reduced lead time and better surface quality to increase their productivity and maintain their competitiveness. In today's manufacturing industries, CNC machine tools play a vital role and have a wide range of applications in machining such as machining centres, turning centres, abrasive water jet machining, electro-discharge machining, etc. 2.5D pocket machining has remarkable applications in aerospace, shipyard, automobile, and dies and moulds industries. More than $80 \%$ of mechanical parts can be cut by applying the concept of pocket machining (Held, 1991). The mathematician at Boeing Company defined pocket machining as "Removal of material from stock, layer by layer until pockets are formed and a manufactured part emerges. The tool path for a layer of a pocket is the centreline path along which a tool - an endmill - is fed as its rotating teeth cut the material" and it is shown in Figure 1 (Bieterman and Sandstrom, 2003). 
Figure 1 Representation of pocket milling operation (see online version for colours)

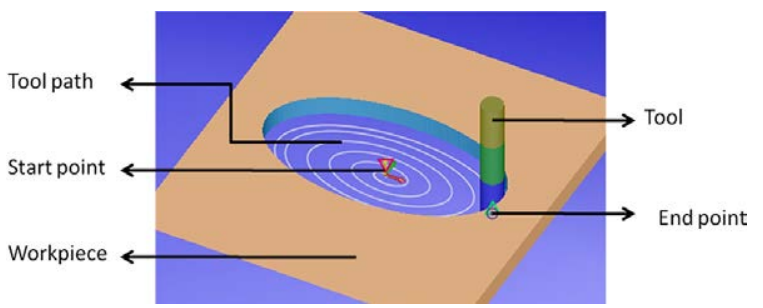

Most of the research related to pocket machining addresses the problem of tool path generation or effect of various cutting parameters such as speed, feed rate and depth of cut. The conventional tool path strategies, the directional parallel tool path and contour parallel tool path are widely used for machining of a pocket and available in many commercial CAD/CAM software, such as Unigraphics, Delcam, Mastercam, Cimatron, etc., because these two tool path strategies are both computationally tractable and geometrically appealing (Xu, Sun and Zhang, 2013). Many references on these conventional tool path strategies, not limited to, are given in references (Monreal and Rodriguez, 2003; Gupta, Saini and Yao, 2001; Choi and Park, 1999; Dhanik and Xirouchakis, 2010; Molina-Carmnoa, Jimeno and Davia, 2008). Recently, literature has shown a growing interest on generation of the spiral tool path for a $2.5 \mathrm{D}$ pocket machining (Xiong, Zhuang and Ding, 2011). The advantages of the spiral tool path over conventional tool path are reported in many references (not limited to) (Banerjee, Feng and Bordatchev, 2012; Chuang and Yang, 2007; Bieterman, 2001; Bieterman and Sandstrom, 2003; Xu, Sun and Zhang, 2013). Held and Spielberger (2013) pointed out that the shape of the pocket affects the suitability of spiral tool path for high speed machining (HSM). For example, if a pocket is very long and narrow (length $>>$ width) or contains a bottle-neck, one spiral tool path may not be efficient to cover the entire pocket.

The literature related to various factors (parameters) settings that affect the pocket machining can be summarised as follows:

1 Cutting conditions, that is, speed, feed rate and depth of cut (Benardos and Vosniakos, 2002; Abou-El-Hossein and Yahya, 2005; Thangarasu, Devaraj and Sivasubramanian, 2013; Agrawal and Joshi, 2013; Hamdan, Sarhan and Hamdi, 2012).

2 cutting fluid (Benardos and Vosniakos, 2002; Xavior and Adithan, 2009)

3 pocket geometry (Romero et al., 2013)

4 Tool path strategy (Romero et al., 2013; Kim and Choi, 2002b; Gologlu and Sakarya, 2008; Toh, 2005; Toh, 2004).

The above factors affect the following:

1 material removal rate (Thangarasu, Devaraj and Sivasubramanian, 2013)

2 cutting time (Kim and Choi, 2002b)

3 Tool wear (Xavior and Adithan, 2009; Abou-El-Hossein and Yahya, 2005; Sahoo and Sahoo, 2012). 
4 Surface roughness (Benardos and Vosniakos, 2002; Xavior and Adithan, 2009; Thangarasu, Devaraj and Sivasubramanian, 2013; Hamdan, Sarhan and Hamdi, 2012; Bhattacharya et al., 2009; Sahoo and Sahoo, 2012).

However, the effect of the shape of pocket and the tool path strategies on a $2.5 \mathrm{D}$ pocket machining is scarcely studied. To study the effect of tool path strategies, zig-zag, contour parallel and spiral tool path are selected. To study the effect of the shape of pocket, an elliptical geometry is selected because an elliptical shape is commonly found in industries and our day-to-day products such as bottles, tiffin box, cups, stools, shape of a clock, a tube for making decorative furniture, mirrors, etc. Manufacturing of these products usually requires generation of an elliptical pocket. Another reason for selecting elliptical geometry is to demonstrate that as the pocket tends to be a circle (i.e. as the aspect ratio increases), the spiral tool path offers several advantages.

In the present work, an experimental investigation using design of experiments (DOE) is carried out to study the effect of aspect ratio (i.e. changing pocket geometry), tool path strategies (zig-zag, spiral and contour parallel), and feed rate on tool path length, cutting time, percentage utilisation of tool (explained in Section 4.1) and average surface roughness $(\mathrm{Ra})$ in machining of elliptical pockets on AISI 304 stainless steel.

A commercially available AISI 304 stainless steel was used for experiments. AISI 304 austenitic stainless steel is widely used in chemical, automotive, marine, aerospace and nuclear industries because of its high oxidation resistance (anti-corrosion properties) along with good weldability and formability. AISI 304 austenitic stainless steel is classified under the category of materials that are very difficult to machine. Machining of these steels is generally accompanied by a number of difficulties such as premature tool failure, poor surface finish due to high temperature at tool-chip interface, irregular wear and built up edge (Tetal, 1989; Xavior and Adithan, 2009; Abou-El-Hossein and Yahya, 2005). The poor machinability of AISI 304 steel is because of very low heat conductivity (50\% of that of plain carbon steels), high ductility, high tensile strength, high fracture toughness and high work hardening rates (Chow, Lee and Yang, 2008).

\section{Experimental details}

\subsection{Tool path strategy and pocket geometry}

The pocket geometry is varied by varying the ratio of minor axis to major axis of ellipse such that the area of the pocket remains constant. Ellipses with an aspect ratio (i.e. ratio of a minor axis to a major axis) as $0.25,0.5$ and 0.75 are selected. The dimensions of the major axis and minor axis for the ellipse with aspect ratio $0.25,0.5$ and 0.75 are $160 \mathrm{~mm} \times 40 \mathrm{~mm}, 113.138 \mathrm{~mm} \times 56.568 \mathrm{~mm}$ and $92.377 \mathrm{~mm} \times 69.282 \mathrm{~mm}$, respectively, such that the area of pocket is equal to $20106 \pm 0.5 \mathrm{~mm}^{2}$. Zig-zag, spirallike and contour parallel tool path strategies are selected. The maximum allowable stepover (i.e., the distance between adjacent tool paths) for each tool path strategy is kept at $50 \%$ of the tool diameter. Figure 2 shows the tool path strategies, namely, zig-zag (top), spiral-like (middle) and contour parallel (bottom) for the ellipse with the aspect ratio of 0.5 . 
Figure 2 Zig-zag (top), spiral-like (middle) and contour parallel (bottom) tool path for ellipse with aspect ratio of 0.5 (see online version for colours)
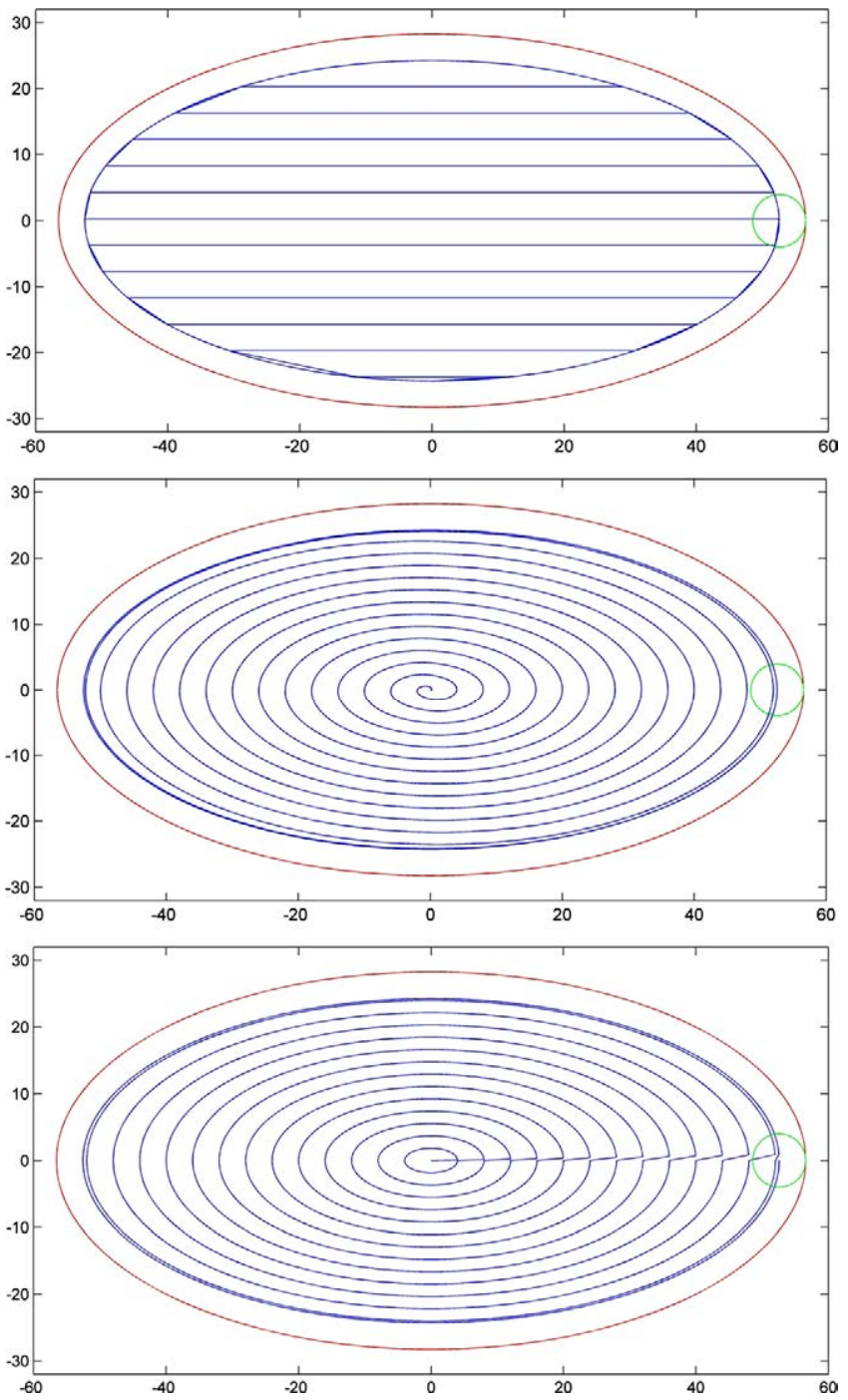

\subsection{Machining conditions and tooling details}

AISI 304 stainless steels are more difficult to machine than ferritic and martensitic stainless steel grade families. Therefore, a standard carbide end-mill-cutter is selected with recommended cutting speed and feed as shown in Table 1 (Cunat, 2008; MCGuire, 2008). The standard, four flutes, carbide end-mill-cutter (Figure 3) has the diameter of $8 \mathrm{~mm}$ and the flute length of $23 \mathrm{~mm}$. As the study is related to HSM, a higher cutting speed of $150 \mathrm{~m} / \mathrm{min}$ is selected for machining and corresponding spindle rotation, $5968.31 \mathrm{rpm}$, is used (rounded to $6000 \mathrm{rpm}$ ). The depth of cut was $0.2 \mathrm{~mm}$. The ESTO CONKUT, grade CX coolant was used for the machining operation. Figure 4 shows the workpiece during and after the machining operation. The machining was carried out on 
HSM centre (Model: VMC 430, Make: Jyoti CNC Automation Ltd.) with SINUMERIC 802 D SL controller. Surface roughness was measured using surface roughness tester (Model: Surftest SJ-201P, Make: Mitutoyo ${ }^{\circledR}$ ).

Table 1 Recommended cutting conditions

\begin{tabular}{lcccc}
\hline $\begin{array}{l}\text { Tool } \\
\text { material }\end{array}$ & Material to cut & $\begin{array}{c}\text { Cutting speed } \\
(\mathrm{m} / \mathrm{min})\end{array}$ & $\begin{array}{c}\text { Feed } \\
(\mathrm{mm} / \mathrm{rev} / \text { tooth })\end{array}$ & $\begin{array}{c}\text { Feed }(\mathrm{mm} / \mathrm{min}) \text { at } \\
6000 \mathrm{rev} / \mathrm{min}\end{array}$ \\
\hline $\begin{array}{l}\text { Carbide } \\
\text { tools }\end{array}$ & $\begin{array}{c}\text { AISI 304 stainless } \\
\text { steel }\end{array}$ & $50-150$ & $0.012-0.125$ & $288-3000$ \\
\hline
\end{tabular}

Cunat, 2008; MCGuire, 2008

Figure 3 Carbide end-mill-cutter with four flutes and diameter of $8 \mathrm{~mm}$ (see online version for colours)

Figure 4 Workpiece during (left) and after (right) machining (see online version for colours)

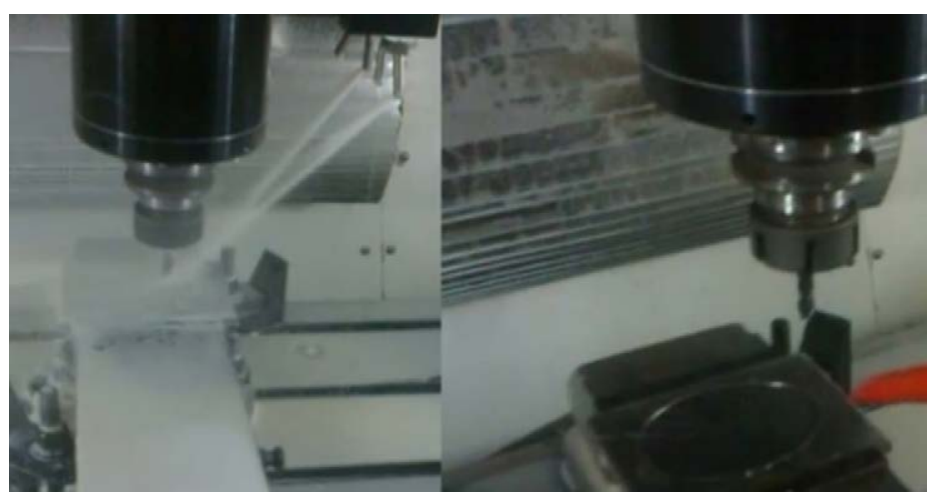

\section{Experimental plan procedure}

The DOE is a systematic, efficient and rigorous approach for planning experiments so that the data obtained can be analysed to draw valid and objective conclusions. In the present work, a 3-level full factorial design for 3-factor, that is, $3^{3}$ is selected (Table 2). The design matrix to conduct the number of experiments (runs) is shown in Table 3 and was generated using Design-Expert ${ }^{\circledR}$ software. The experiments were conducted as per 'run order' column. Table 3 shows the standard run order, experiment run order, factor levels and responses measured (tool path length, cutting time and percentage utilisation of tool and $\mathrm{Ra}$ ) for all 27 runs. Since there are three levels for each factor, the design allows the relationship between the response and the factors to be modelled as non-linear. The factors such as aspect ratio, feed rate and tool path strategy are denoted by A, B and $\mathrm{C}$, respectively. 
Table 2 Factors with their respective levels for a $3^{3}$ design in brief

\begin{tabular}{llcccc}
\hline \multirow{2}{*}{$\begin{array}{l}\text { Factors } \\
\text { (parameters) }\end{array}$} & Factors name & Factor type & Low $(-1)$ & Medium (0) & High (-1) \\
\cline { 4 - 6 } A & $\begin{array}{l}\text { Aspect ratio (minor } \\
\text { axis to major axis) of } \\
\text { ellipse }\end{array}$ & Numeric & 0.25 & 0.5 & 0.75 \\
B & Feed rate & Numeric & 288 & 1644 & 3000 \\
C & Tool path strategy & Categorical & $\begin{array}{l}\text { Contour } \\
\text { parallel }\end{array}$ & Spiral-like & Zig-zag \\
\hline
\end{tabular}

Table 3 Design matrix with responses

\begin{tabular}{|c|c|c|c|c|c|c|c|c|}
\hline & & Factor 1 & Factor 2 & Factor 3 & Response 1 & Response 2 & Response 3 & Response 4 \\
\hline $\begin{array}{l}\text { Std. } \\
\text { order }\end{array}$ & $\begin{array}{l}\text { Run } \\
\text { order }\end{array}$ & $\begin{array}{c}\text { A: } \\
\text { Aspect } \\
\text { ratio }\end{array}$ & $\begin{array}{c}\text { B: Feed } \\
\text { rate } \\
(\mathrm{mm} / \mathrm{min})\end{array}$ & $\begin{array}{c}\text { C: Tool } \\
\text { path } \\
\text { strategy }\end{array}$ & $\begin{array}{l}\text { Tool path } \\
\text { length } \\
(\mathrm{mm})\end{array}$ & $\begin{array}{l}\text { Cutting } \\
\text { time }(s)\end{array}$ & $\begin{array}{c}\text { Percentage } \\
\text { utilisation }\end{array}$ & $\begin{array}{c}\text { Surface } \\
\text { roughness, } \\
R a(\mu m)\end{array}$ \\
\hline 1 & 15 & 0.25 & 288 & Zig-zag & 1340.6 & 280 & 93.7366 & 0.44 \\
\hline 2 & 27 & 0.50 & 288 & Zig-zag & 1338.82 & 280 & 93.8618 & 0.53 \\
\hline 3 & 25 & 0.75 & 288 & Zig-zag & 1334.22 & 279 & 94.1852 & 0.62 \\
\hline 4 & 18 & 0.25 & 1644 & Zig-zag & 1340.6 & 50 & 93.7366 & 1.57 \\
\hline 5 & 11 & 0.50 & 1644 & Zig-zag & 1338.82 & 50 & 93.8618 & 1.14 \\
\hline 6 & 6 & 0.75 & 1644 & Zig-zag & 1334.22 & 50 & 94.1852 & 0.71 \\
\hline 7 & 13 & 0.25 & 3000 & Zig-zag & 1340.6 & 28 & 93.7366 & 2.20 \\
\hline 8 & 23 & 0.50 & 3000 & Zig-zag & 1338.82 & 28 & 93.8618 & 1.54 \\
\hline 9 & 10 & 0.75 & 3000 & Zig-zag & 1334.22 & 29 & 94.1852 & 0.88 \\
\hline 10 & 4 & 0.25 & 288 & Spiral-like & 3366.8 & 702 & 37.3243 & 0.38 \\
\hline 11 & 3 & 0.50 & 288 & Spiral-like & 2104.38 & 439 & 59.7154 & 0.37 \\
\hline 12 & 16 & 0.75 & 288 & Spiral-like & 1547.41 & 323 & 81.2088 & 0.36 \\
\hline 13 & 7 & 0.25 & 1644 & Spiral-like & 3366.8 & 124 & 37.3243 & 1.27 \\
\hline 14 & 24 & 0.50 & 1644 & Spiral-like & 2104.38 & 78 & 59.7154 & 0.96 \\
\hline 15 & 26 & 0.75 & 1644 & Spiral-like & 1547.41 & 57 & 81.2088 & 0.65 \\
\hline 16 & 14 & 0.25 & 3000 & Spiral-like & 3366.8 & 70 & 37.3243 & 1.95 \\
\hline 17 & 8 & 0.50 & 3000 & Spiral-like & 2104.38 & 44 & 59.7154 & 1.41 \\
\hline 18 & 9 & 0.75 & 3000 & Spiral-like & 1547.41 & 33 & 81.2088 & 0.87 \\
\hline 19 & 20 & 0.25 & 288 & Contour & 3267.49 & 681 & 38.4588 & 0.29 \\
\hline 20 & 2 & 0.50 & 288 & Contour & 2024.54 & 422 & 62.0703 & 0.37 \\
\hline 21 & 17 & 0.75 & 288 & Contour & 1468.75 & 307 & 85.5584 & 0.44 \\
\hline 22 & 19 & 0.25 & 1644 & Contour & 3267.49 & 121 & 38.4588 & 1.02 \\
\hline
\end{tabular}


Table 3 Design matrix with responses (continued)

\begin{tabular}{lcccccccc}
\hline & & Factor 1 & Factor 2 & Factor 3 & Response 1 & Response 2 & Response 3 & Response 4 \\
\cline { 2 - 8 } $\begin{array}{l}\text { Std. } \\
\text { order }\end{array}$ & $\begin{array}{c}\text { Run } \\
\text { order }\end{array}$ & $\begin{array}{c}\text { Aspect } \\
\text { ratio }\end{array}$ & $\begin{array}{c}\text { B: Feed } \\
\text { rate } \\
(\mathrm{mm} / \mathrm{min})\end{array}$ & $\begin{array}{c}\text { C: Tool } \\
\text { path } \\
\text { strategy }\end{array}$ & $\begin{array}{c}\text { Tool path } \\
\text { length } \\
(\mathrm{mm})\end{array}$ & $\begin{array}{c}\text { Cutting } \\
\text { time }(\mathrm{s})\end{array}$ & $\begin{array}{c}\text { Percentage } \\
\text { utilisation }\end{array}$ & $\begin{array}{c}\text { Surface } \\
\text { roughness, } \\
\text { Ra }(\mu \mathrm{m})\end{array}$ \\
\hline 23 & 12 & 0.50 & 1644 & Contour & 2024.54 & 75 & 62.0703 & 0.87 \\
24 & 22 & 0.75 & 1644 & Contour & 1468.75 & 55 & 85.5584 & 0.72 \\
25 & 1 & 0.25 & 3000 & Contour & 3267.49 & 68 & 38.4588 & 1.58 \\
26 & 5 & 0.50 & 3000 & Contour & 2024.54 & 43 & 62.0703 & 1.23 \\
27 & 21 & 0.75 & 3000 & Contour & 1468.75 & 31 & 85.5584 & 0.89 \\
\hline
\end{tabular}

\section{Results and discussions}

The results are analysed using Design-Expert ${ }^{\circledR}$ and Minitab ${ }^{\circledR}$ software. The objective of the analysis is to determine the individual or combined (interaction) effect of aspect ratio, feed rate and tool path strategy on the tool path length, the cutting time, percentage utilisation of the tool and the average surface roughness. From Table 3, following important observations are made and given in Table 4.

Table 4 Range of responses

\begin{tabular}{llcc}
\hline Sr. no & Response (units) & Lower limit & Upper limit \\
\hline 1 & Tool path length $(\mathrm{mm})$ & 1334.22 & 3366.8 \\
2 & Cutting time (s) & 28 & 702 \\
3 & Percentage utilisation of tool & 37.3243 & 94.1852 \\
4 & Average surface roughness, $\mathrm{Ra}(\mu \mathrm{m})$ & 0.29 & 2.2 \\
\hline
\end{tabular}

\subsection{Tool path length}

The main effect plots for the tool path length are shown in Figure 5. It is clear from Figure 5 that feed rate (factor B) does not affect the tool path length as slope angle is negligible (very less). However, both aspect ratio (factors A) and tool path strategy (factor C) affect the tool path length. As the aspect ratio (factor A) of ellipse increases, the tool path length decreases. Also, tool path length is almost same for both spiral-like tool path and contour parallel, whereas tool path length for zig-zag decreases drastically. 
Figure 5 Main effect plot for tool path length

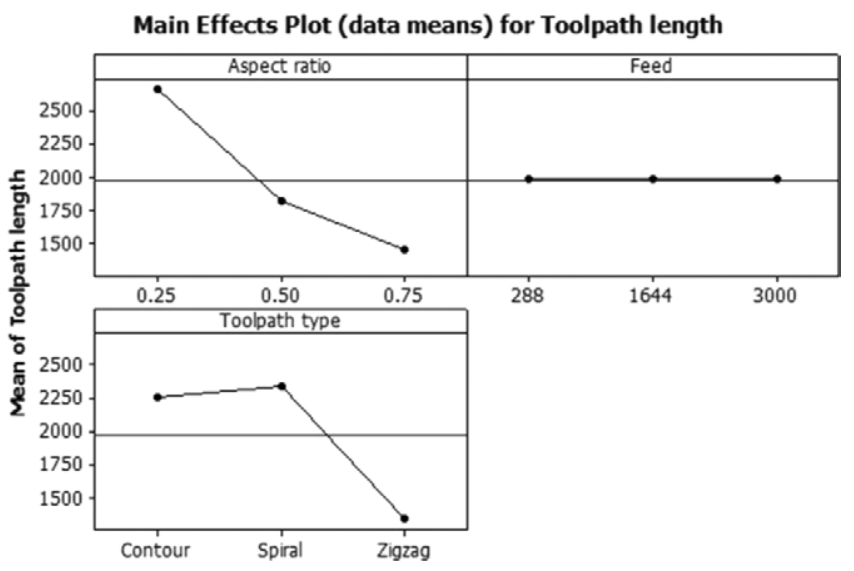

The interaction plots for the tool path length are shown in Figure 6; it is clear that as the lines are almost parallel, there is no interaction between 'aspect ratio (factor A) and feed rate (factor B)' and 'feed rate (factor B) and tool path strategy (factor C)', but synergistic interaction (i.e. lines on the plot do not cross each other) between aspect ratio (factor $\mathrm{A}$ ) and tool path strategy (factor C) is observed (Antony, 2003). The interaction between aspect ratio and tool path strategy indicates that tool path length for zig-zag tool path, with different aspect ratios $(0.25,0.5$ and 0.75 shown by black, red and green lines, respectively), is almost constant, whereas the tool path length for contour parallel and spiral-like tool path decreases as the aspect ratio increases.

Figure 6 Interaction effect plot for tool path length (see online version for colours)

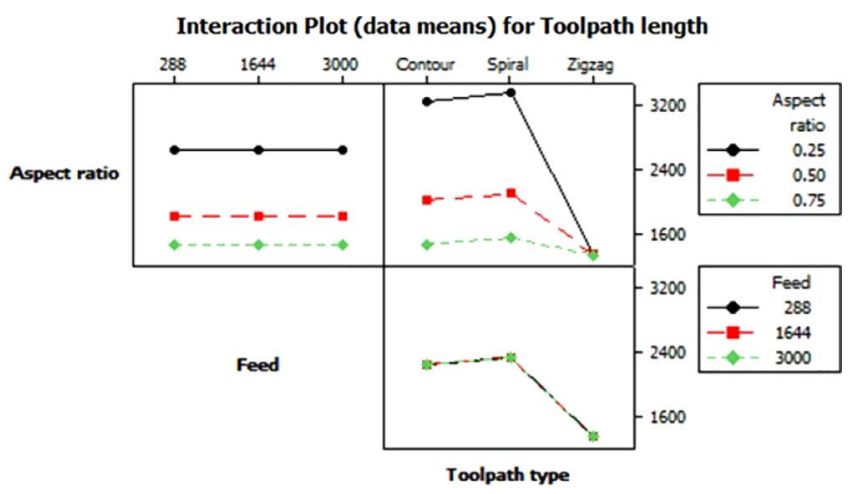

Table 5 shows the analysis of variance (ANOVA) (partial sum of square) for tool path length after removing insignificant terms (statistically not affecting the response) along with Standard Deviation (Std. Dev.), mean, coefficient of variance (C.V) and various $R^{2}$ statistics (i.e. $R^{2}$, adjusted $R^{2}\left(R_{\text {Adj }}^{2}\right)$ and predicted $R^{2}\left(R_{\text {Pred }}^{2}\right)$ ). The $p$ value for the model is less than 0.05 indicating that the model is significant. Furthermore, tool path length depends on the aspect ratio $(A)$, tool path strategy $(C), \mathrm{AC}$ and $A^{2}$ as the obtained $p$ value is less than 0.05 ( $95 \%$ confidence interval). 
Table 5 ANOVA (partial sum of square) for tool path length after removing insignificant terms

\begin{tabular}{lcccccr}
\hline Source & $\begin{array}{c}\text { Sum of } \\
\text { squares }\end{array}$ & $d f$ & Mean square & Fvalue & $\begin{array}{c}\text { Prob }>F \\
(\text { p value })\end{array}$ & Remarks \\
\hline Model & 15688124.54 & 6 & 2614687.423 & 320.8068098 & $<0.0001$ & Significant \\
A: Aspect ratio & 6568556.305 & 1 & 6568556.305 & 805.9233293 & $<0.0001$ & \\
C: Tool path strategy & 5547663.612 & 2 & 2773831.806 & 340.332892 & $<0.0001$ & \\
AC & 3249974.734 & 2 & 1624987.367 & 199.3764182 & $<0.0001$ & \\
$A^{2}$ & 321929.8891 & 1 & 321929.8891 & 39.49890904 & $<0.0001$ & \\
Residual & 163006.9776 & 20 & 8150.348881 & & & \\
Cor total & 15851131.52 & 26 & & & & \\
Std. dev. & 90.27928268 & & $R^{2}$ & 0.9897 & & \\
Mean & 1977.000842 & & $R_{\text {Adj }}^{2}$ & 0.9866 & & \\
C.V. \% & 4.566476694 & $R_{\text {Pred }}^{2}$ & 0.9827 & & \\
\hline
\end{tabular}

The value of $R^{2}=0.9897$ for the tool-path-length model indicates that model explains $98.97 \%$ of the total variations. The adjusted $R^{2}$ is a statistic that is adjusted for the "size" of the model, that is, the number of factors (terms) which are significant. The value of $R_{\mathrm{Adj}}^{2}=0.9866$ indicates that $98.66 \%$ of the total variability is explained by the model after considering the significant factors that affect response. $R_{\text {Pred }}^{2}=0.9827$ is in good agreement with the $R_{\mathrm{Adj}}^{2}$ and shows that the model would be expected to explain $98.27 \%$ of the variability in new data (Montgomery, 2013). The 'C.V.' stands for the coefficient of variation of the model and it is the error expressed as a percentage of the mean ( $(\mathrm{Std}$. Dev./Mean) * 100). The lower value of the coefficient of variation $(\mathrm{C} . \mathrm{V} .=4.56 \%)$ indicates improved precision and reliability of the conducted experiments. The response equations of tool path for zig-zag, contour parallel and spiral-like tool path are given below.

$$
\begin{aligned}
\text { Toolpath length for zigzag type }= & 2116.38286-3718.93763 * \text { Aspect ratio } \\
& +3706.16719 * \text { Aspect ratio }{ }^{2} \pm \text { error } \\
\text { Toolpath length for spiral-like type }= & 4931.04041-7344.94804 * \text { Aspect ratio } \\
& +3706.16719 * \text { Aspect ratio }{ }^{2} \pm \text { error } \\
\text { Toolpath length for contour type }= & 4824.44925-7303.64691 * \text { Aspect ratio }^{2} \\
+ & 3706.16719 * \text { Aspect ratio }^{2} \pm \text { error }
\end{aligned}
$$

Figure 7 shows the comparison between the predicted values from the model (above response equations) and the actual values (Table 3) for tool path length. The average absolute \% error was found as 4.25 . 
Figure 7 Actual vs. predicted value of tool path length (see online version for colours)

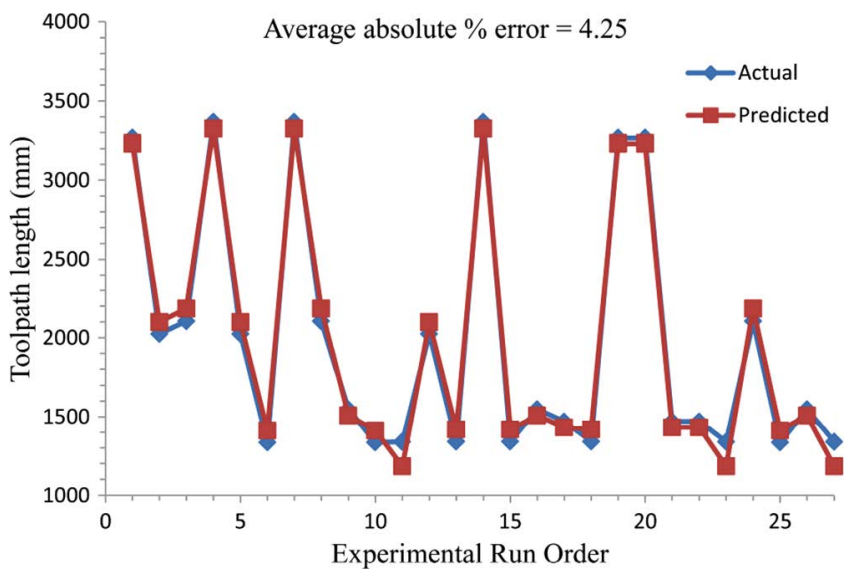

The same procedure was applied on cutting time, percentage utilisation of the tool and average surface roughness, and the resulting ANOVA with $R^{2}$ statistics for reduced models (considering only the significant terms) are shown in Tables $6-8$, respectively.

Table 6 ANOVA (partial sum of square) for cutting time after removing insignificant terms

\begin{tabular}{lcccccc}
\hline Source & $\begin{array}{c}\text { Sum of } \\
\text { squares }\end{array}$ & $d f$ & Mean square & $F$ value & $\begin{array}{c}\text { Prob }>F \\
(p \text { value })\end{array}$ & Remarks \\
\hline Model & 952354.2315 & 10 & 95235.42315 & 32.48287963 & $<0.0001$ & Significant \\
A: Aspect ratio & 51200 & 1 & 51200 & 17.46328606 & 0.0007 & \\
B: Feed & 619384.5 & 1 & 619384.5 & 211.259545 & $<0.0001$ & \\
C: Tool path & 43316.51852 & 2 & 21658.25926 & 7.387194861 & 0.0053 & \\
strategy & & & & & & \\
AB & 38646.75 & 1 & 38646.75 & 13.18162598 & 0.0022 & \\
AC & 25603 & 2 & 12801.5 & 4.366333134 & 0.0307 & \\
BC & 32420.33333 & 2 & 16210.16667 & 5.528960498 & 0.0149 & \\
$B^{2}$ & 141783.1296 & 1 & 141783.1296 & 48.35936231 & $<0.0001$ & \\
Residual & 46909.84259 & 16 & 2931.865162 & & & \\
Cor. total & 999264.0741 & 26 & & & & \\
Std. dev. & 54.14670038 & & $R^{2}$ & 0.9530 & & \\
Mean & 175.8148148 & & $R_{\text {Adj }}^{2}$ & 0.9237 & & \\
C.V.\% & 30.79757553 & & $R_{\text {Pred }}^{2}$ & 0.8194 & & \\
\hline
\end{tabular}


Table 7 ANOVA (partial sum of square) for percentage utilisation after removing insignificant terms

\begin{tabular}{lcccccc}
\hline Source & $\begin{array}{c}\text { Sum of } \\
\text { squares }\end{array}$ & $d f$ & Mean square & Fvalue & $\begin{array}{c}\text { Prob }>F \\
(\text { p value })\end{array}$ & Remarks \\
\hline Model & 12862.88105 & 5 & 2572.57621 & 125597.1087 & $<0.0001$ & Significant \\
A: Aspect ratio & 4179.970211 & 1 & 4179.970211 & 204072.5445 & $<0.0001$ & \\
$\begin{array}{l}\text { C: Tool path } \\
\text { strategy }\end{array}$ & 6646.245294 & 2 & 3323.122647 & 162239.9348 & $<0.0001$ & \\
AC & 2036.665545 & 2 & 1018.332772 & 49716.56483 & $<0.0001$ & \\
Residual & 0.43013809 & 21 & 0.020482766 & & & \\
Cor. total & 12863.31119 & 26 & & & & \\
Std. dev. & 0.143118015 & & $R^{2}$ & 0.9999 & & \\
Mean & 71.79108864 & $R_{\text {Adj }}^{2}$ & 0.9999 & & \\
C.V. \% & 0.199353454 & $R_{\text {Pred }}^{2}$ & 0.9999 & & \\
\hline
\end{tabular}

Table 8 ANOVA (partial sum of square) for Ra after removing insignificant terms

\begin{tabular}{lcccccc}
\hline Source & $\begin{array}{c}\text { Sum of } \\
\text { squares }\end{array}$ & $d f$ & Mean square & $F$ value & $\begin{array}{c}\text { Prob }>F \\
(p \text { value })\end{array}$ & Remarks \\
\hline Model & 6.774605556 & 7 & 0.967800794 & 119.5117788 & $<0.0001$ & Significant \\
$\begin{array}{l}\text { A: Aspect } \\
\text { ratio }\end{array}$ & 1.1552 & 1 & 1.1552 & 142.6533309 & $<0.0001$ & \\
$\begin{array}{l}\text { B: Feed } \\
\text { : Tool }\end{array}$ & 4.253472222 & 1 & 4.253472222 & 525.2527532 & $<0.0001$ & \\
path & 0.280466667 & 2 & 0.140233333 & 17.31713306 & $<0.0001$ & \\
strategy & & & & & & \\
AB & 0.963333333 & 1 & 0.963333333 & 118.9601011 & $<0.0001$ & \\
AC & 0.122133333 & 2 & 0.061066667 & 7.541000181 & 0.0039 & \\
Residual & 0.153861111 & 19 & 0.008097953 & & & \\
Cor. total & 6.928466667 & 26 & & & & \\
Std. dev. & 0.089988628 & & $R^{2}$ & 0.9777 & & \\
Mean & 0.935555556 & & $R_{\text {Adj }}^{2}$ & 0.9696 & & \\
C.V. \% & 9.618736988 & & $R_{\text {Pred }}^{2}$ & 0.9456 & & \\
\hline
\end{tabular}

\subsection{Cutting time}

Calculation of the cutting (machining) time for a given tool path is a pre-requisite for planning the machining processes. The theoretical machining time $=$ tool path length/feed rate. The calculated theoretical machining time is little underestimation $(\Delta t)$ of the actual machining time (Appendix 1), because it does not take into account the effects of the acceleration and deceleration which takes places when a tool encounters a corner or a 
sharp curvature (Bieterman and Sandstrom, 2003; Kim and Choi, 2002a). The actual cutting time for machining elliptical pockets is shown in Table 3.

The main effect and interaction effect plots for cutting time are shown in Figures 8 and 9 , respectively. The main effect plots show the following:

1 As the aspect ratio of the geometry increases from 0.25 to 0.75 , the cutting time decreases.

2 As the feed rate increases from 288 to $1644 \mathrm{~m} / \mathrm{min}$, there is a drastic decrease in cutting time as compared to the feed rate increases from 1644 to $3000 \mathrm{~m} / \mathrm{min}$.

3 Cutting time is minimum for the zig-zag tool path followed by the contour parallel and spiral-like tool path.

Figure 8 Main effect plot for cutting time

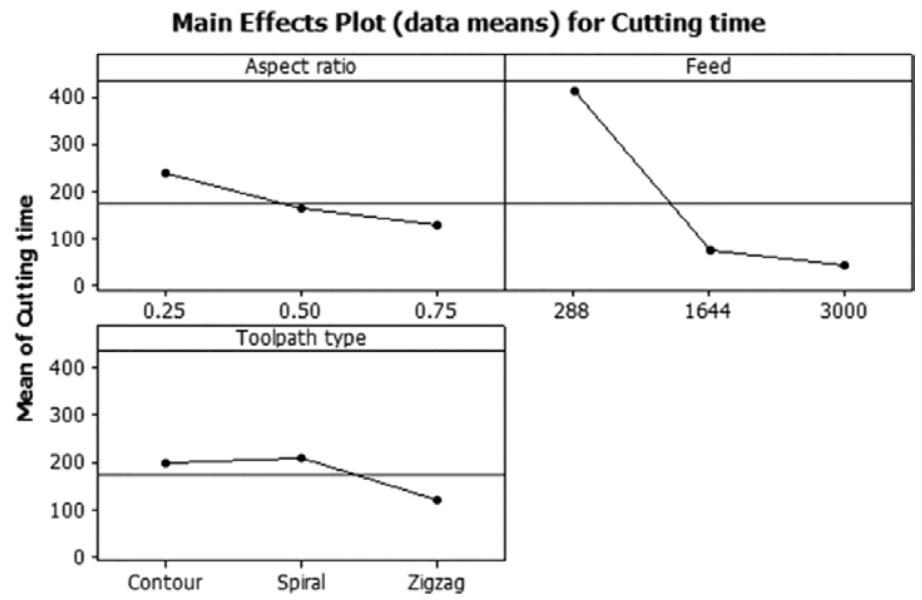

Figure 9 Interaction effect plot for cutting time (see online version for colours)

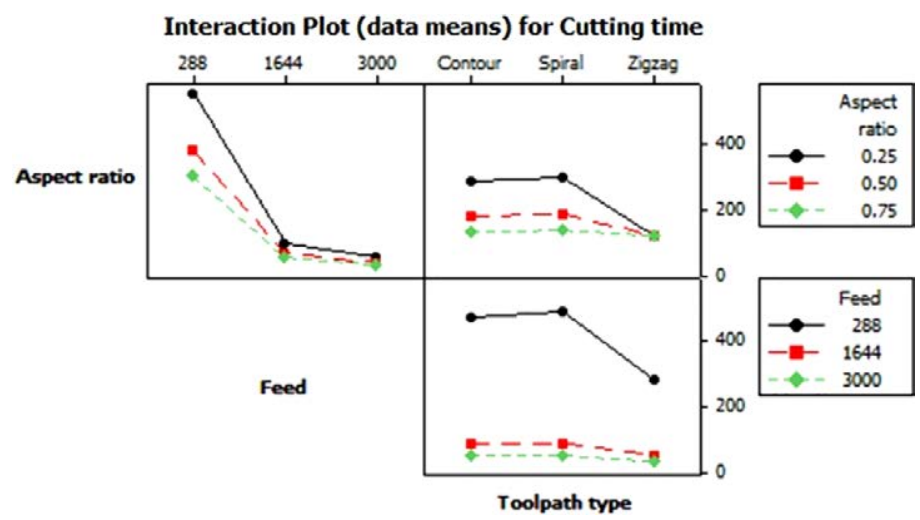

In the case of the contour parallel and spiral-like tool paths, as the aspect ratio of pocket geometry decreases, the step-over along the minor axis decreases which results in the increase in the tool path length for the same area of pocket. Thus, the pocket geometry with higher aspect ratio (i.e. the pocket geometry is closer to the circular geometry) gives 
lower cutting time as compared to pocket geometry with a lower aspect ratio (i.e. the pocket geometry is away from the circular geometry) for the same area of the pocket.

The interaction effect plots for the cutting time indicate that interactions are present between all the three factors as the lines are not parallel (Antony, 2003). Interaction between aspect ratio (factor $A$ ) and feed rate (factor $B$ ) indicates that minor difference is observed for cutting time at feed rate $=3000 \mathrm{~mm} / \mathrm{min}$ for aspect ratio of 0.25 (black), 0.5 (red) and 0.75 (green), whereas the difference between cutting time increases as the feed rate decreases from 1644 to $288 \mathrm{~mm} / \mathrm{min}$. The interaction of aspect ratio (factor $A$ ) and tool path strategy (factor $C$ ) indicates that cutting time for zig-zag, with different aspect ratio $(0.25,0.5$ and 0.75 shown by black, red and green lines, respectively) is almost constant, whereas the cutting time for contour parallel and spiral-like tool path decreases as the aspect ratio increases from 0.25 to 0.75 . The interaction of feed rate (factor $B$ ) and tool path strategy (factor $C$ ) indicates that at lower feed rate of 288 (black), there is a large difference in cutting time for zig-zag tool path as compared to spiral-like and contour parallel tool path, whereas difference in cutting time is very small at feed rate of 1644 (red) and 3000 (green) for zig-zag, spiral-like and contour parallel tool path, respectively.

The equations of cutting time for zig-zag, contour parallel and spiral-like tool path are given below.

$$
\begin{aligned}
\text { Cutting time }(s) \text { for zigzag toolpath }= & 532.76943-275.21239 * \text { Aspect ratio } \\
& -0.45126 * \text { Feed }+0.16740 * \text { Aspect ratio } * \text { Feed } \\
& +8.36021 * 10^{-5} * \text { Feed }^{2} \pm \text { error }
\end{aligned}
$$

Cutting time $(s)$ for spiral-liketoolpath $=895.97641-597.21239 *$ Aspect ratio

$$
\begin{aligned}
& -0.52046 * \text { Feed }+0.16740 * \text { Aspect ratio } * \text { Feed } \\
& +8.36021 * 10^{-5} * \text { Feed }^{2} \pm \text { error }
\end{aligned}
$$

Cutting time $(s)$ for contour parallel toolpath $=876.63079-593.21239 *$ Aspect ratio

$$
\begin{aligned}
& -0.51444 * \text { Feed }+0.16740 * \text { Aspect ratio } * \\
& \text { Feed }+8.36021 * 10^{-5} * \text { Feed }^{2} \pm \text { error }
\end{aligned}
$$

The predicted values from the model (above response equations) and the actual values (Table 3) for cutting time (s) are shown in Figure 10 as per experimental run order.

Figure 10 Actual vs. predicted value of cutting time (see online version for colours)

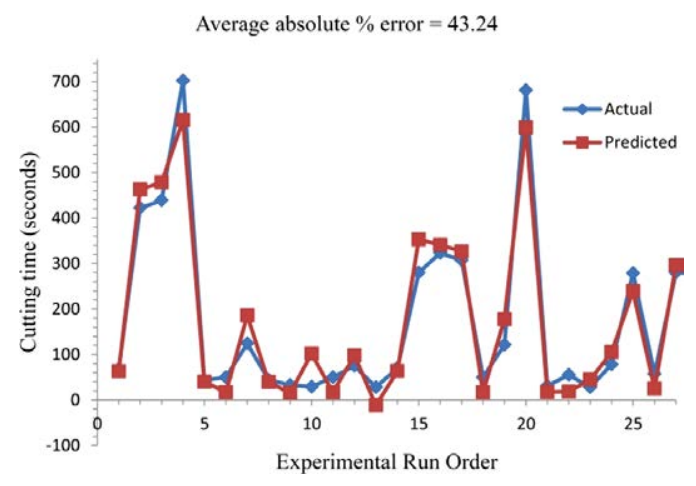




\subsection{Percentage utilisation of a tool}

The maximum value of step-over for zig-zag, spiral-like and contour parallel tool path is $50 \%$ of tool diameter. In contour parallel and spiral-like tool paths, the value of step-over decreases along the minor axis as the aspect ratio of the pocket geometry decreases. Thus, the tool does not cut at its full capacity which results in increases tool path length and cutting time as discussed in Sections 4.1 and 4.2. Percentage utilisation of a tool (PUT), for a tool path strategy, is defined as the ratio of pocket area to cutting-area swept by a tool for a given layer of a pocket multiplied by 100 . Thus, it is written as follows

$$
\begin{aligned}
\text { Percentage utilization of a tool }(P U T) & =\frac{\text { area of the pocket }}{\text { cutting area swept bytool }} * 100 \\
& =\frac{A}{L^{*} D * S} * 100
\end{aligned}
$$

where $A$ is the area of the pocket to be machined, $L$ is the length of the tool path, $D$ is the diameter of a cutter and $S$ is step-over (and it is given as percentage of cutter diameter) divided by $100\left(S=\frac{\text { Step over in } \%}{100}\right)$.

Thus, PUT depends on area of material removed, tool path length, step-over and diameter of a cutter, and it quantifies the degree to which a tool is performing cutting at the intended capacity. Figure 11 shows the main effect plots for percentage utilisation of tool and it reveals that feed rate does not affect percentage utilisation of tool. However, both aspect ratio and tool path strategy affect PUT. As the aspect ratio of ellipse increases (i.e. pocket tends to be a circle), PUT increases because the pocket tends to be circle, the squeezing of tool path along the minor axis decreases. The squeezing of the tool path along the minor axis for the elliptical pocket with lower aspect ratio indicates that the tool has to pass through a narrow region again-and-again with very little or no quantity of material removal in each pass, resulting in increased tool path length and machining time. Also, percentage utilisation of tool is maximum for the zig-zag tool path, followed by the contour parallel and spiral-like tool path.

Figure 11 Main effect plot for percentage utilisation of tool

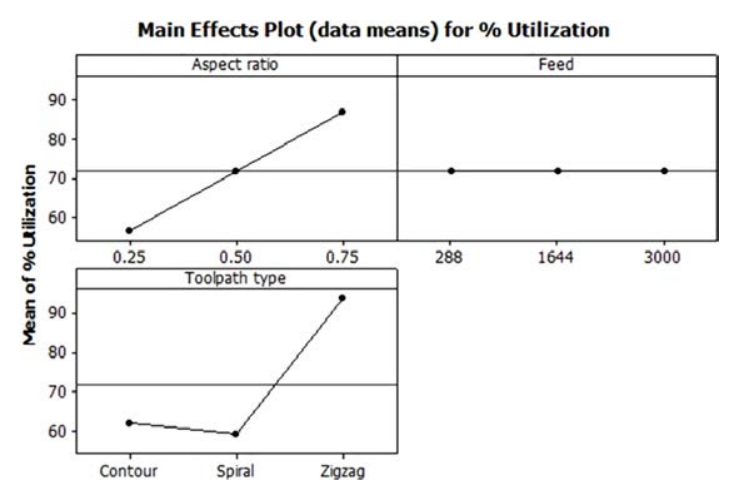

The interaction plots for percentage utilisation of tool are shown in Figure 12; from the plots, it is clear that as the lines are almost parallel, there is no interaction between 
'aspect ratio (factor $A$ ) and feed rate (factor $B$ )' and 'feed rate (factor $B$ ) and tool path strategy (factor $C$ )', but synergistic interaction (i.e. lines on the plot do not cross each other) between aspect ratio (factor $A$ ) and tool path strategy (factor $C$ ) is observed (Antony, 2003). The interaction between aspect ratio and tool path strategy indicates that percentage utilisation of the tool for zig-zag tool path, with different aspect ratio $(0.25$, 0.5 and 0.75 shown by black, red and green lines, respectively) is the highest and almost constant, whereas the percentage utilisation of the tool for contour parallel and spiral-like tool path increases as the aspect ratio increases.

Figure 12 Interaction effect plot for percentage utilisation of tool (see online version for colours)

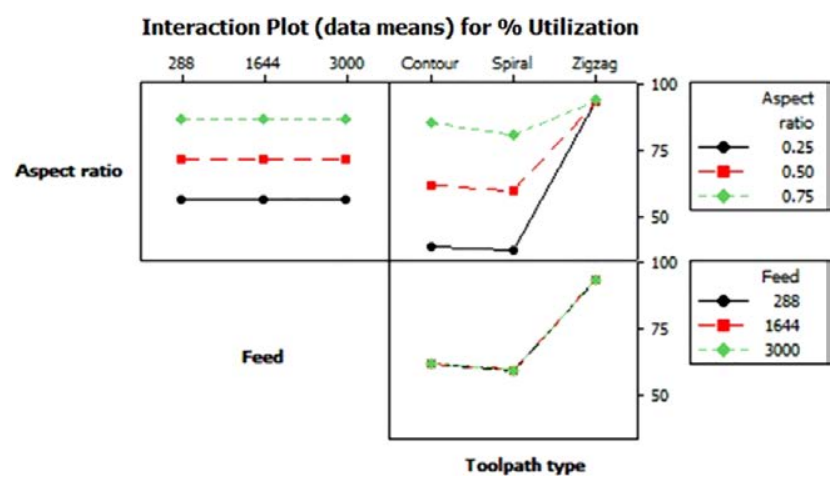

The equations of percentage utilisation of tool for zig-zag, contour parallel and spiral-like tool path are given below.

Percentage utilization for zigzag toolpath $=93.47930+0.89720 *$ Aspect ratio \pm error

Percentage utilization for spiral-like toolpath $=15.53167+87.76903 *$ Aspect ratio

$$
\pm \text { error }
$$

Percentage utilization for contour parallel toolpath $=14.92958+94.19919$

$$
\text { * Aspect ratio } \pm \text { error }
$$

Figure 13 shows the predicted values from the model (above equations) and the actual values (Table 3 ) for percentage utilisation of the tool as per experimental run order.

Figure 13 Actual vs. predicted values for percentage utilisation of tool (see online version for colours)

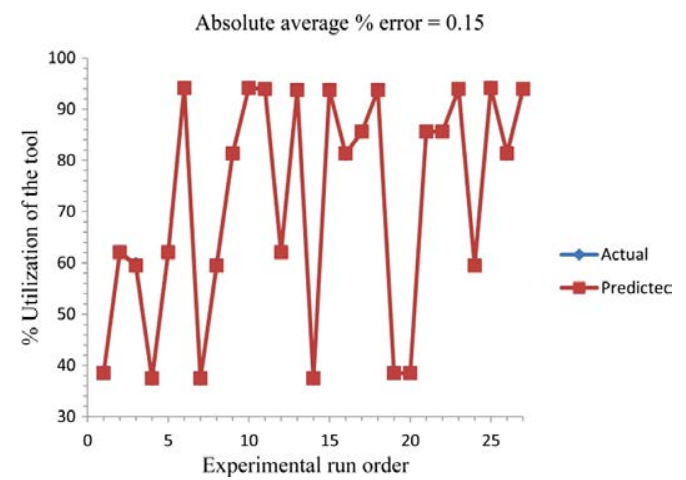




\subsection{Average surface roughness}

One of the most important requirements of the finished product is surface quality. Average surface roughness (Ra) is mostly used as an indication of surface quality. Ra depends on various controllable process parameters such as spindle speed, feed rate, depth of cut, hardness of the material, wet or dry machining, dynamic forces on the job, tool wear rate, cutter geometry, etc. (Thangarasu, Devaraj and Sivasubramanian, 2013).

Figure 14 shows the main effect plots for Ra and it reveals that all the factors affect $\mathrm{Ra}$. The Ra decreases as the aspect ratio increases from 0.25 to 0.75 , whereas the Ra increases as the feed rate increases from 288 to $3000 \mathrm{~mm} / \mathrm{min}$. Contour parallel tool path gives a minimum value of averaged $\mathrm{Ra}$ as compared to the spiral-like and zig-zag tool path.

Figure 14 Main effect plot for surface roughness (Ra)

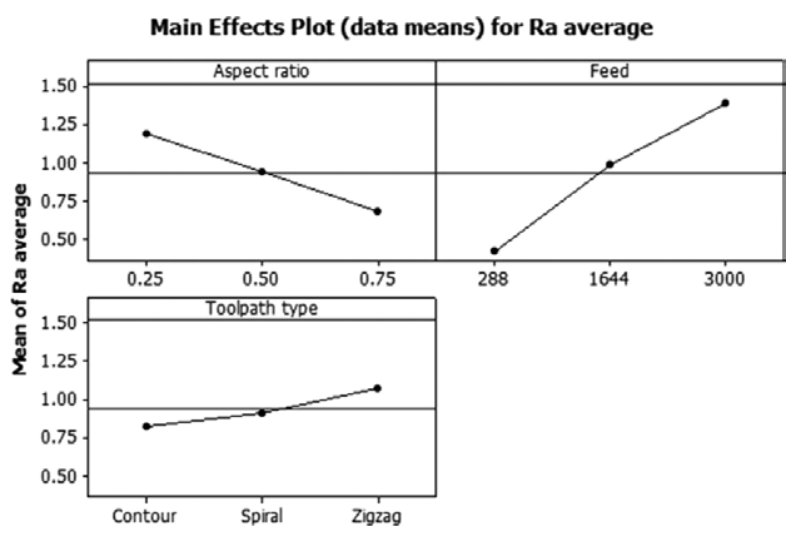

Figure 15 shows the interaction plots for surface roughness; it is clear that there is no much interaction between 'feed rate (factor $B$ ) and tool path strategy (factor $C$ )' and 'aspect ratio (factor $A$ ) and tool path strategy (factor $C$ )' as the lines are almost parallel but the interaction between 'aspect ratio (factor $A$ ) and feed rate (factor $B$ )' is present. The interaction between 'aspect ratio (factor $A$ ) and feed rate (factor $B$ )' indicates that at lower feed rate of $288 \mathrm{~mm} / \mathrm{min}$, for all aspect ratio (i.e. $0.25,0.5$ and 0.75 ), the value of $\mathrm{Ra}$ is almost same. But as the feed rate increases, the Ra increases with a higher rate for a lower aspect ratio as shown by black (0.25), red (0.5) and green (0.75) lines, respectively. The equations of Ra for zig-zag, contour parallel and spiral-like tool path are given below.

$$
\begin{aligned}
\text { Surface Roughness for zigzag toolpath }= & 0.46029+0.040708 * \text { Aspect ratio }+7.76385 * 10^{-4} \\
& * \text { Feed }-8.35792 * 10^{-4} * \text { Aspect ratio } * \text { Feed } \pm \text { error }
\end{aligned}
$$

Surface Roughness for spiral-liketoolpath $=0.21029+0.22737 *$ Aspect ratio

$$
\begin{aligned}
& +7.76385 * 10^{-4} * \text { Feed }-8.35792 * 10^{-4} \\
& * \text { Aspect ratio * Feed } \pm \text { error }
\end{aligned}
$$

Surface Roughness for contour parallel toolpath $=-0.17304+0.81404 *$ Aspect ratio

$$
\begin{aligned}
& +7.76385 * 10^{-4} * \text { Feed }-8.35792 \\
& * 10^{-4} * \text { Aspect ratio * Feed } \pm \text { error }
\end{aligned}
$$


Figure 15 Interaction effect plot for surface roughness (Ra) (see online version for colours)

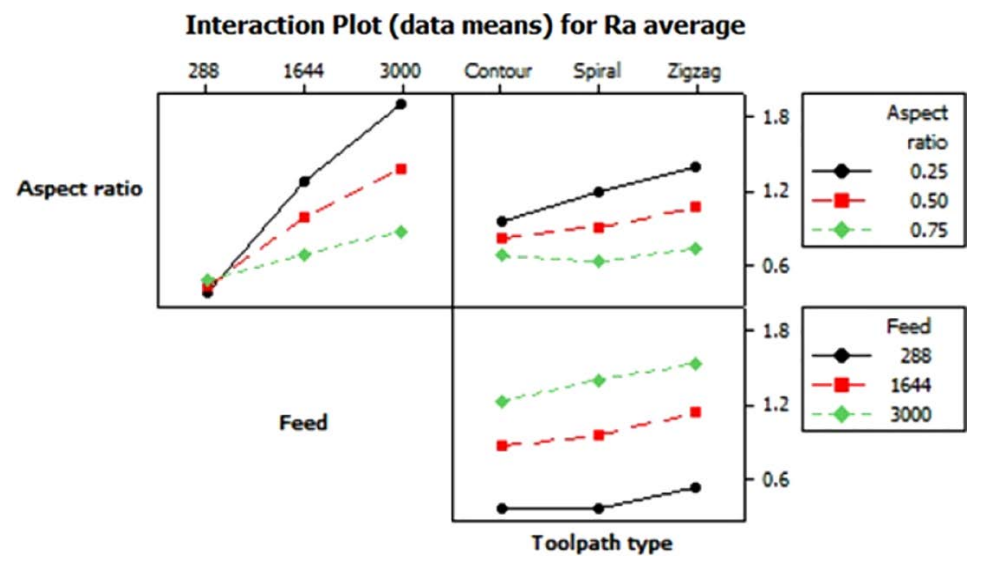

Figure 16 shows the predicted values from the model (above equations) and the actual values (Table 3 ) for average surface roughness as per experimental run order.

Figure 16 Actual vs. predicted values for surface roughness (Ra) (see online version for colours)

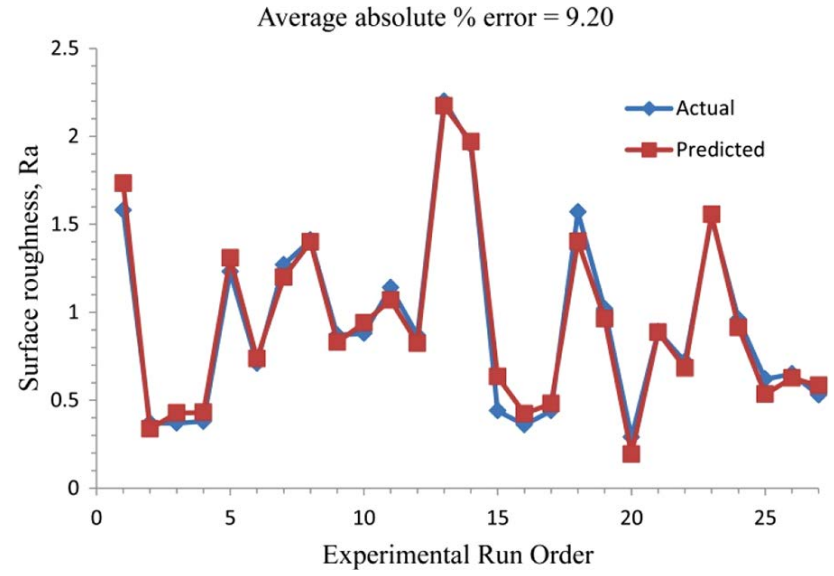

Figures 17-19 show the Ra contour profiles in aspect ratio and feed rate plane for zig-zag, contour parallel and spiral-like tool paths, respectively. These graphs help to identify feed rates for a given aspect ratio to achieve desired $\mathrm{Ra}$ value. For example, while machining with zig-zag, spiral-like and contour parallel tool path, to achieve Ra of $0.8 \mu \mathrm{m}$ for different aspect ratio of $0.38,0.5$ and 0.63 , the feed rate should be ' $f_{z 1}, f_{z 2}$ and $f_{z 3}$ ', ' $f_{s 1}, f_{s 2}$ and $f_{s 3}$ ' and ' $f_{c 1}, f_{c 2}$ and $f_{c 3}$ ', respectively, as shown in Figures 17-19. 
Figure 17 Surface roughness contour in aspect ratio (A) and feed rate (B) plane for zig-zag tool path (see online version for colours)

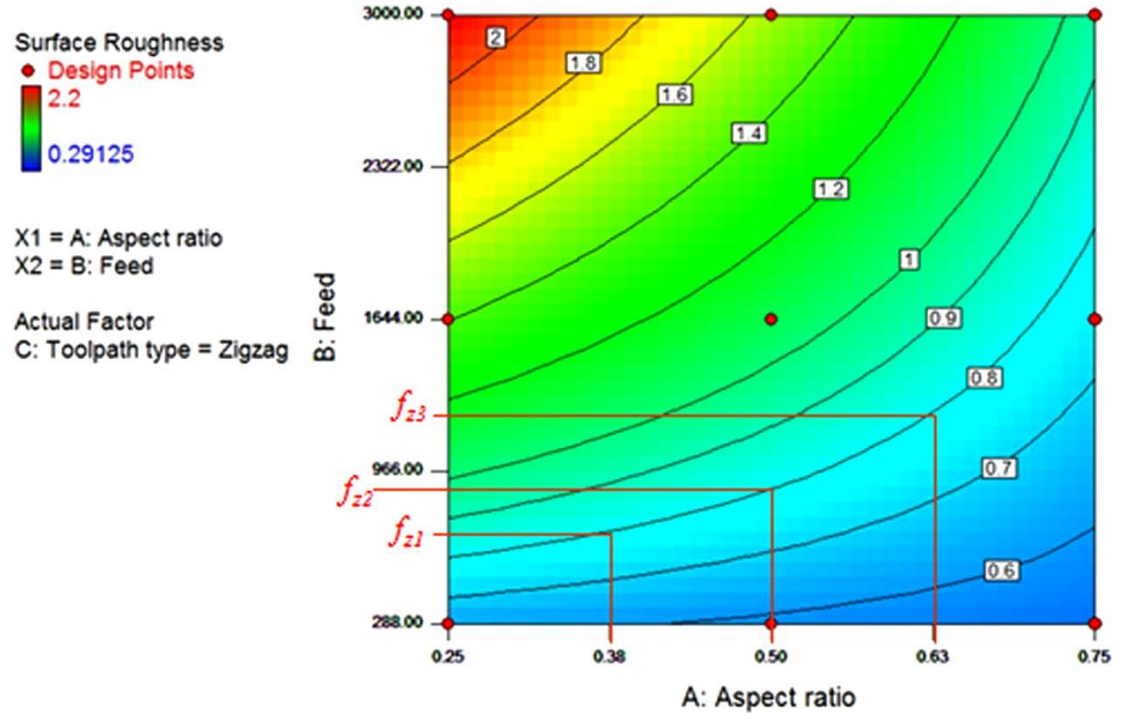

Figure 18 Surface roughness contour in aspect ratio (A) and feed rate (B) plane for spiral-like tool path (see online version for colours)

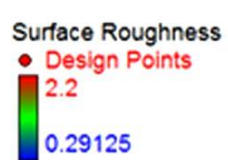

$\mathrm{X}_{1}=\mathrm{A}:$ Aspect ratio $X 2=B:$ Feed

Actual Factor C: Toolpath type $=$ Spiral

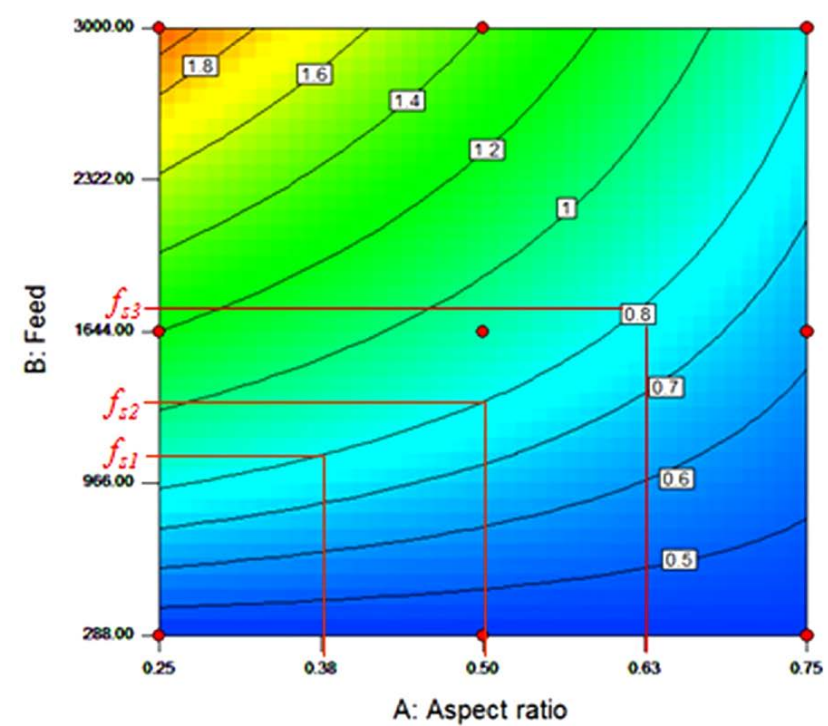

A: Aspect ratio 
Figure 19 Surface roughness contour in aspect ratio (A) and feed rate (B) plane for contour tool path (see online version for colours)

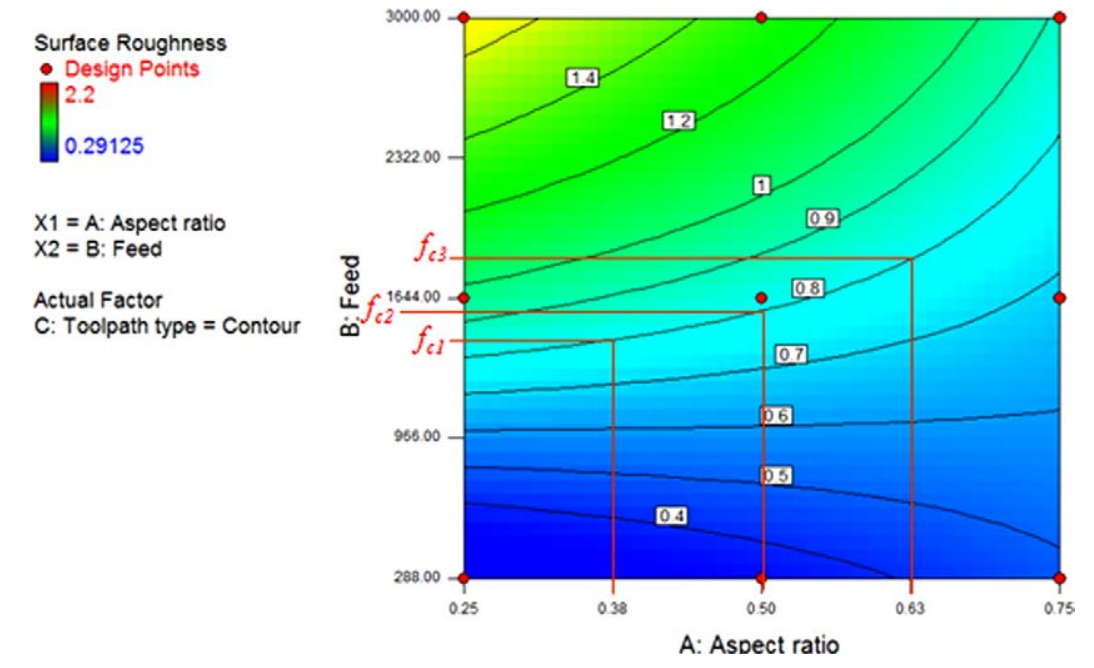

\section{Conclusion and scope of future work}

This paper presents experimental investigation of the effect of aspect ratio, feed rate and tool path strategy on tool path length, cutting time, percentage utilisation of tool and Ra for elliptical pocket machining on AISI 304 steel using carbide end-mill-cutter and the following conclusions are drawn:

- The quadratic model best fits the variation in tool path length and cutting time, whereas 2-factor interaction model best fits the variation in percentage utilisation of the tool and average surface roughness.

- Aspect ratio and tool path strategy affect the tool path length and percentage utilisation of tool, whereas aspect ratio, feed rate and tool path strategy affect cutting time and average surface roughness.

- The response equations (predictive model) of tool path length, cutting time, percentage utilisation of tool and surface roughness (Ra) for zig-zag, contour parallel and spiral-like tool path, respectively, are developed.

- Good surface finish, enhancement in percentage utilisation of the tool, reduced tool path length and cutting time are obtained when the aspect ratio of an ellipse increases from 0.25 to 0.75 (i.e. an elliptical pocket tends to be a circular pocket).

- Reduction in cutting time and increase in surface roughness (Ra) is obtained as feed rate increases from 288 to $3000 \mathrm{~mm} / \mathrm{min}$, whereas no change is observed on tool path length and percentage utilisation of the tool.

- The longest tool path length and highest cutting time are obtained for spiral-like tool path strategy followed by contour parallel and zig-zag type. 
- Percentage utilisation of tool is very low for spiral-like tool path followed by contour parallel tool path as compared to zig-zag tool path.

- The lowest surface roughness $(\mathrm{Ra})$ is obtained for the contour parallel tool path followed by the spiral-like and zig-zag tool path.

- Surface roughness contour plots in aspect ratio and feed rate plane for zig-zag, spiral-like and contour parallel tool paths are developed. These plots can be used for selecting the feed for a given aspect ratio to achieve desired surface roughness.

The findings of this study indicate that the shape of pocket plays an important role in high-speed pocket machining. Hence, our future work aims to develop a method/technique for quantitative comparison of different pocket geometries. Also, if a pocket is very long (i.e. very high aspect ratio) or has a bottle-neck, then decomposing (dividing) such pocket geometry can greatly reduce the tool path length, machining time and increase PUT.

\section{References}

Abou-El-Hossein, K.A. and Yahya, Z. (2005) 'High-speed end-milling of AISI 304 stainless steels using new geometrically developed carbide inserts', Journal of Materials Processing Technology, Vol. 162-163, pp.596-602.

Agrawal, S. and Joshi, S.S. (2013) 'Analytical modelling of residual stresses in orthogonal machining of AISI4340 steel', Journal of Manufacturing Processes, Vol. 15, No. 1, pp.167-179.

Antony, J. (2003) Design of Experiments for Engineers and Scientists, Butterworth-Heinemann, Oxford.

Banerjee, A., Feng, H-Y. and Bordatchev, E.V. (2012) 'Process planning for floor machining of $2 \frac{1}{2} \mathrm{D}$ pockets based on a morphed spiral tool path pattern', Computers \& Industrial Engineering Comput Ind Eng, Vol. 63, No. 4, pp.971-979.

Benardos, P.G. and Vosniakos, G.C. (2002) 'Prediction of surface roughness in CNC face milling using neural networks and Taguchi's design of experiments', Robotics and ComputerIntegrated Manufacturing, Vol. 18, No. 5-6, pp.343-354.

Bhattacharya, A., Das, S., Majumder, P. and Batish, A. (2009) 'Estimating the effect of cutting parameters on surface finish and power consumption during high speed machining of AISI 1045 steel using Taguchi design and ANOVA', Production Engineering, Vol. 3, No. 1, pp. $31-40$

Bieterman, M. (2001) 'Mathematics in manufacturing: new approach cuts milling costs', Siam News, Vol. 34, No. 7, pp.1-3.

Bieterman, M.B. and Sandstrom, D.R. (2003) 'A curvilinear tool path method for pocket machining', Journal of Manufacturing Science and Engineering Transactions of the ASME, Vol. 125, pp.709-715.

Choi, B.K. and Park, S.C. (1999) 'A pair-wise offset algorithms for 2D point-sequence curve', Comput Aided Design, Vol. 31, pp.735-745.

Chow, H-M., Lee, S-M. and Yang, L-D. (2008) 'Machining characteristic study of friction drilling on AISI 304 stainless steel', Journal of Materials Processing Technology, Vol. 207, No. 1-3, pp.180-186. 
Chuang, J-J. and Yang, D.C.H. (2007) 'A laplace based spiral contouring method for general pocket machining', The International Journal of Advanced Manufacturing Technology, Vol. 34, pp.714-723.

Cunat, P-J. (2008) Working with Stainless Steels, Materials and Applications Series, Volume 2, $2^{\text {nd }}$ ed., EDP Sciences and Euro Inox, Sirpe, Paris.

Dhanik, S. and Xirouchakis, P. (2010) 'Contour parallel milling tool path generation for arbitrary pocket shape using a fast marching method', The International Journal of Advanced Manufacturing Technology, Vol. 50, No. 9-12, pp.1101-1111.

Gologlu, C. and Sakarya, N. (2008) 'The effects of cutter path strategies on surface roughness of pocket milling of 1.2738 steel based on Taguchi method', Journal of Material Processing Technology, Vol. 206, pp.7-15.

Gupta, S.K., Saini, S.K. and Yao, Z. (2001) 'An algorithm to generate efficient cutter path for pocket milling operations using modified zigzag strategy', Proceedings of the ASME Design Engineering Technical Conferences, Pittsburgh, Pennsylvania, United States, Sep 9 to 12, 2001, Vol. 1, ASME, pp.709-718.

Hamdan, A., Sarhan, A.D. and Hamdi, M. (2012) 'An optimization method of the machining parameters in high-speed machining of stainless steel using coated carbide tool for best surface finish', The International Journal of Advanced Manufacturing Technology, Vol. 58, No. 1-4, pp.81-91.

Held, M. and Spielberger, C. (2013) 'Improved Spiral High-Speed Machining of MultiplyConnected Pockets', Comput Aided Design Appl, Vol. 11, No. 3, pp.346-357.

Held, M. (1991) On the Computational Geometry of Pocket Machining, Springer Science \& Business Media, Berlin.

Kim, B.H. and Choi, B.K. (2002a) 'Machining efficiency comparision direction-parallel tool path with contour-parallel tool path', Computer Aided Design, Vol. 34, pp.89-95.

Kim, B.H. and Choi, B.K. (2002b) 'Machining efficiency comparison direction-parallel tool path with contour-parallel tool path', Computer-Aided Design, Vol. 34, No. 2, pp.89-95.

MCGuire, M.F. (2008) Stainless Steels for Design Engineers, ASM International, Ohio, USA.

Molina-Carmnoa, R., Jimeno, A. and Davia, M. (2008) 'Contour pocketing computation using mathematical morphology', International Journal of Advanced Manufacturing Technology, Vol. 36, pp.334-342.

Monreal, M. and Rodriguez, C.A. (2003) 'Influence of tool path strategy on the cycle time of highspeed milling', Comput Aided Design, Vol. 35, pp.395-401.

Montgomery, D.C. (2013) Design and Analysis of Experiments, 8th ed., John Wiley \& Sons, Inc, Hoboken, New Jersey.

Romero, P.E., Dorado, R., Díaz, F.A. and Rubio, E.M. (2013) 'Influence of pocket geometry and tool path strategy in pocket milling of UNS A96063 alloy', Procedia Engineering, Vol. 63, pp.523-531.

Sahoo, A.K. and Sahoo, B. (2012) 'Experimental investigations on machinability aspects in finish hard turning of AISI 4340 steel using uncoated and multilayer coated carbide inserts', Measurement, Vol. 45, No. 8, pp.2153-2165.

Tetal, K. (1989) Machining of Stainless Steels Handbook, 9th ed., ASM International, Ohio, USA.

Thangarasu, V., Devaraj, G. and Sivasubramanian, R. (2013) 'High speed CNC machining of AISI 304 stainless steel; optimization of process parameters by MOGA', International Journal of Engineering, Science and Technology, Vol. 4, No. 3, pp.66-77.

Toh, C.K. (2004) 'A study of the effects of cutter path strategies and orientations in milling', Journal of Materials Processing Technology, Vol. 152, No. 3, pp.346-356.

Toh, C.K. (2005) 'Design, evaluation and optimisation of cutter path strategies when high speed machining hardened mould and die materials', Materials and Design, Vol. 26, pp.517-533. 
Xavior, M.A. and Adithan, M. (2009) 'Determining the influence of cutting fluids on tool wear and surface roughness during turning of AISI 304 austenitic stainless steel', Journal of Materials Processing Technology, Vol. 209, No. 2, pp.900-909.

Xiong, Z., Zhuang, C. and Ding, H. (2011) 'Curvilinear tool path generation for pocket machining', Proceedings of the Institution of Mechanical Engineers, Part B: Journal of Engineering Manufacture, Vol. 225, No. 4, pp.483-495.

Xu, J., Sun, Y. and Zhang, X. (2013) 'A mapping-based spiral cutting strategy for pocket machining', International Journal of Advanced Manufacturing Technology, Vol. 67, No. 9-12, pp.2489-2500.

\section{Appendix 1: Underestimation of machining time ( $\Delta t)$}

Underestimated time $\Delta t=2 n\left[\frac{f^{2}-a d}{a f}\right]$

Where

$f=$ feed rate,

$a=$ acceleration and deceleration when tool encounter a sharp corner,

$d=$ stopping distance and

$n=$ number of corners encountered. 